\title{
Vitamin E Improves Biochemical Indices Associated with Symptoms of Atopic Dermatitis-Like Inflammation in NC/Nga Mice
}

\author{
Daisuke HAYASHI ${ }^{1}$, Hotaka SugAYA $^{1}$, Takayuki OHKOSHI ${ }^{1}$, Kaori SEKIZAWA ${ }^{1}$, \\ Hirokatsu TAKATSU ${ }^{1}$, Tadashi SHINKAI ${ }^{2}$ and Shiro URANO ${ }^{3, *}$ \\ ${ }^{1}$ Division of Biological Chemistry, Shibaura Institute of Technology, 3-7-5 Toyosu, \\ Kohtoh-ku, Tokyo 135-8548, Japan \\ ${ }^{2}$ Redox Regulation Research Group, Tokyo Metropolitan Institute of Gerontology, \\ 35-2 Sakae-cho, Itabashi-ku, Tokyo 173-0015, Japan \\ ${ }^{3}$ Division of Biochemistry, Shibaura Institute of Technology, 307 Fukasaku, \\ Minuma-ku, Saitama 337-8570, Japan
}

(Received December 27, 2011)

\begin{abstract}
Summary We aimed to define whether vitamin E improves biochemical indices associated with symptoms of atopic dermatitis-like inflammation in NC/Nga mice. After picryl chloride (PC) application to their backs, changes in the content of thiobarbituric acid reactive substances (TBARS) and vitamin E, as well as the activity of antioxidant enzymes (superoxide dismutase (SOD), glutathione peroxidase (GSHPx) and catalase) were analyzed in the serum and skin of NC/Nga mice during a symptomatic cycle. The levels of inflammatory factors were also assessed, including IgE, cyclooxigenase-2 (COX-2), tumor necrosis factor (TNF- $\alpha$ ) and nuclear factor- $\kappa \mathrm{B}(\mathrm{NF}-\kappa \mathrm{B})$. When allergic dermatitis was induced by the application of PC to the skin of the mice, skin inflammation appeared $2 \mathrm{wk}$ after PC application, with the peak severity of inflammation observed $5 \mathrm{wk}$ after PC application. Subsequently, the animals recovered from the inflammation by $9 \mathrm{wk}$ after PC application. The TBARS content in the skin and serum increased markedly when the symptoms were the most severe, and decreased to levels near those in control mice by $9 \mathrm{wk}$ after PC application. The activities of SOD and GSHPx in the skin and serum were also positively correlated with symptomatic changes; however, no change in catalase activity was observed $5 \mathrm{wk}$ after PC application. Conversely, vitamin E content decreased at the stage of peak severity. The levels of all inflammatory factors analyzed in this study were altered in a manner similar to other indices. Additionally, vitamin E treatment markedly inhibited these PC-induced alterations. On the basis of these results, it is expected that the observed alterations in biochemical indices, which reflect the symptomatic cycle, may be applicable to objective diagnosis and treatment for atopic dermatitis, and that vitamin E may improve the symptoms of AD.
\end{abstract}

Key Words vitamin E, atopic dermatitis, biochemical indices, oxidative stress, cytokine

Atopic dermatitis (AD) is a chronic and intractable inflammatory skin disorder that is induced through genetic and environmental factors, including altered innate and adaptive immune responses. AD is characterized by a frequently repeated pathophysiological cycle through moderate-severe-moderate allergic conditions. Previously, physicians have diagnosed AD based on their medical experiences and subjective observations of the symptoms. Consequently, it is important to assess changes in diagnostic indices through the symptomatic cycle for an objective understanding of pathophysiological progress in $\mathrm{AD}$. Although the cause of $\mathrm{AD}$ is not entirely clear, the etiology involves an imbalance between two types of helper T-cell (Th-cell), the Th1and Th2-cells. Once Th2-cells are activated, the levels of Th2-related cytokines, such as interleukin (IL)-4, IL-5 and IL-13, are highly increased. IL-5, in particular,

\footnotetext{
*To whom correspondence should be addressed.

E-mail: urano@sic.shibaura-it.ac.jp
}

stimulates B-cells to induce immunoglobulin E (IgE), which subsequently binds to mast cells, leading to the production of prostaglandins and thromboxanes that contribute to allergic reactions in $\mathrm{AD}(1-3)$. These prostanoid compounds arise from arachidonic acid through enzymatic reactions mediated by cyclooxygenase (COX) and lipoxygenase (LOX). There are two COX isozymes, COX-1 and COX-2, with the contribution of COX-2 being especially important in inducing inflammation. In practice, increased levels of COX-2 have been observed in patients with $\mathrm{AD}$ (4). Upon stimulation, activation of COX-2 results in the generation of reactive oxygen species (ROS), further accelerating inflammation. These observations indicate that AD patients are subjected to oxidative stress. In fact, it has been suggested that increased ROS and lipid peroxides may underlie the pathogenesis of $\mathrm{AD}$ due to increased serum levels of nitric oxide (NO) and thiobarbituric acid reactive substances (TBARS), together with an imbalance in the antioxidant defense systems $(5,6)$. Furthermore, 
there is a positive correlation between NO, TBARS, and superoxide dismutase (SOD), as well as a negative correlation with erythrocyte catalase, and the duration of lichen planus (LP) (7). Thus, an increase in oxidative stress and an imbalance in the antioxidant defense mechanisms are characteristics of dermatosis, such as AD. Inflammatory cells, especially macrophages and $\mathrm{T}$ cells, infiltrate into the epidermis in inflamed skin and secrete inflammatory cytokines such as tumor necrosis factor (TNF)- $\alpha$, interferon (IFN)- $\gamma$, or interleukin (IL)-6. TNF- $\alpha$ is a pivotal inflammatory cytokine in the innate immune response and a key factor in skin inflammation (8). Since TNF- $\alpha$ expression is regulated by activation of the transcription factor nuclear factor- $\kappa \mathrm{B}(\mathrm{NF}-\kappa \mathrm{B})$, and TNF- $\alpha$ itself induces NF- $\kappa$ B activation, TNF- $\alpha$ activation may play a pivotal role in the immune and inflammatory responses $(9,10)$. Although it has been suggested that these factors are involved in the manifestation of $\mathrm{AD}$, currently there are no reports that examine biochemical indices of $\mathrm{AD}$ with respect to the moderatesevere-moderate allergic symptom cycle.

In recent years, specific functions of vitamin $\mathrm{E}$ that are independent of its antioxidant effect have been characterized (11). These functions are likely to be due to specific interactions between vitamin $\mathrm{E}$ and enzymes, structural proteins, lipids and transcription factors. In fact, vitamin E inhibits cell proliferation, platelet aggregation and monocyte adhesion, as well as inflammatory factors such as IgE, COX, TNF- $\alpha$ and NF- $\kappa \mathrm{B}$ (12). Consequently, it is important to assess whether vitamin $\mathrm{E}$ improves pathophysiological and biochemical changes through the symptomatic cycle of AD. This study was undertaken to establish whether changes in these indices correlate with the severity of experimental $\mathrm{AD}$ symptoms, and to determine whether vitamin $\mathrm{E}$ inhibits these biochemical changes in the picryl chloride (PC)induced mouse model of AD.

\section{MATERIALS AND METHODS}

Materials.

Animals: All animal experiments were performed with the permission of the Animal Protection and Ethics Committee of the Shibaura Institute of Technology. Animals used in the AD model, 3-wk-old male NC/ Nga mice, were purchased from Japan SLC, Inc. (Hamamatsu, Japan).

Chemicals: Glutathione, hematin, trizma base and glutathione reductase were purchased from Sigma Chemical Co. (MO, USA); SOD analytical kit from Wako Pure Chemical Industries, Ltd. (Osaka, Japan); and bovine COX-2 from Cayman Chemical Co. (MI, USA). All other chemicals were of the highest grade available.

Antibodies: Mouse IgE, goat anti-mouse IgE-affinity purified and goat anti-mouse IgE-HRP conjugates were purchased from Bethyl Laboratories Inc. (TX, USA); Mouse TNF- $\alpha$ ELISA kit (Thermo Fisher Scientific, IL, USA); NF- $\kappa$ B p65 sandwich ELISA kit (Cell Signaling Technology, MA, USA); mouse monoclonal anti-mouse COX-2 (Roboscreen GmbH, Leipzig, Germany); HRPlinked anti-rabbit secondary antibody (Promega Corpo- ration, Madison, WI, USA) and anti-mouse $\beta$-actin (Sigma Chemical Co.).

Assessment of skin features and severity of inflammation through symptomatic cycle of AD. Three-week-old NC/ Nga mice were subcutaneously injected in their backs with a $4 \%$ solution of RRR- $\alpha$-tocopherol in dimethylsulfoxide ( $100 \mu \mathrm{L}, 200 \mathrm{mg} / \mathrm{kg}$ body mass) every other day for $2 \mathrm{wk}$ before PC sensitization. The backs of control mice and vitamin E-treated mice ( $5 \mathrm{wk}$ old) were sensitized with a 5\% PC solution in a mixture of ethanol and acetone $(4: 1)$ on a different region from the vitamin Etreated region. At $4 \mathrm{~d}$ after sensitization, a $0.05 \% \mathrm{PC}$ solution in olive oil was applied to their backs. The severity of inflammation was assessed at 2, 5 and $9 \mathrm{wk}$ after PC application.

Analyses of TBARS and vitamin E contents in the skin and serum. After rats were sacrificed by decapitation, blood samples were collected in test tubes and each sample was centrifuged at $5,800 \times g$ for $10 \mathrm{~min}$ at $4^{\circ} \mathrm{C}$ to obtain the serum. The back skin of the inflamed region was cut and frozen immediately using a liquid nitrogen bath. Frozen skin samples were powdered by crushing with a hammer, suspended in a phosphate buffered saline (PBS), and then homogenized using a glass/Teflon homogenizer in an ice bath. The homogenates were centrifuged at $5,800 \times g$ for $10 \mathrm{~min}$ at $4^{\circ} \mathrm{C}$, with the supernatants used in subsequent analyses. The supernatants and serum samples were diluted 10 times in PBS. Protein content was quantitated using the BioRad protein assay reagent (Bio-Rad Laboratories, Inc., CA, USA).

TBARS levels in the skin and serum were measured under acidic conditions as previously reported by Ohkawa et al. (13). The content of TBARS is expressed as nanomolar equivalents of malondialdehyde per milligram of protein. For analysis of vitamin E contents in the skin and serum, an aliquot of the sample was mixed with $2 \mathrm{~mL}$ of a $6 \%$ pyrogallol solution in ethanol, $35 \%$ $\mathrm{KOH}$ solution and 2-methyl-2-(4,8,12-trimethyltridecyl)chroman-6-ol (240 pmol) as an internal standard. The mixture was saponified at $100^{\circ} \mathrm{C}$ for $45 \mathrm{~min}$ and, after cooling, the mixture was extracted with a solution of hexane and ethyl acetate $(9: 1)$. The extract was evaporated using nitrogen gas, and analyzed by reversephase HPLC with electrochemical detection (Shiseido, Tokyo, Japan).

Measurement of antioxidative enzymes in the skin and serum. The activity of SOD in each sample was analyzed by monitoring the reduction of nitroblue tetrazolium using an SOD analysis kit (SOD Test, Wako). The activities of catalase and glutathione peroxidase (GSHPx) were assessed according to previously reported methods $(14,15)$.

Measurement of total IgE and COX-2 expression in the skin and serum. The levels of total IgE in the skin and serum were assessed using a sandwich enzyme-linked immunosorbent assay (ELISA) method. A 96-well plate was coated with goat anti-mouse IgE by incubating for $24 \mathrm{~h}$ at room temperature. To block non-specific binding, the wells were washed for $3 \mathrm{~min}$ at room tempera- 

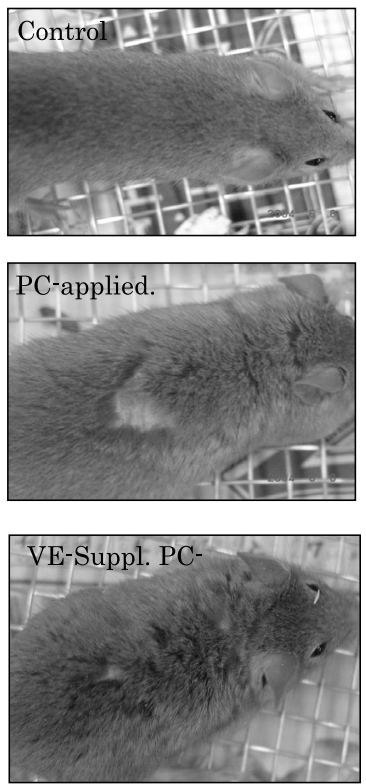

$5 \mathrm{wk}$
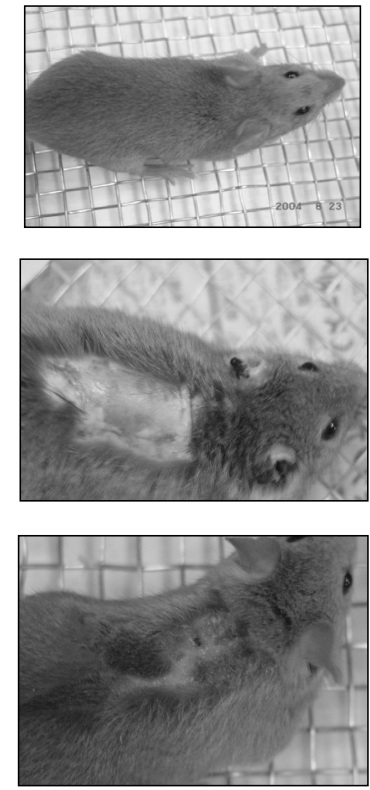

8 wk
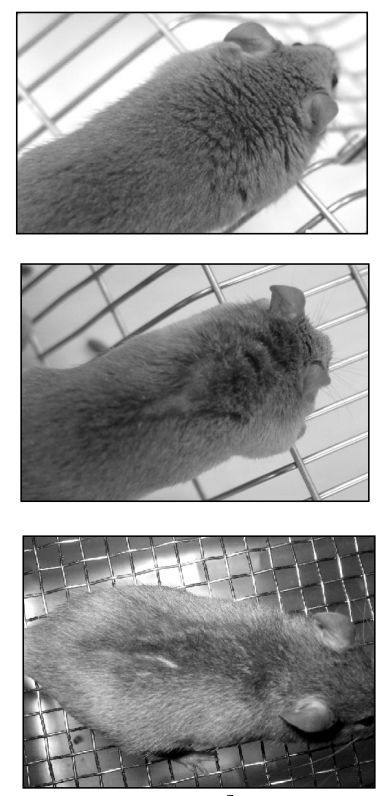

$12 \mathrm{wk}$

Fig. 1. Changes in skin features of dermatitis through the symptomatic cycle in NC/Nga mice with topical application of PC.

ture with washing solution $(1 \%$ bovine serum albumin (BSA) in PBS containing $0.6 \%$ trizma base, $0.05 \%$ Tween 20 and $0.8 \% \mathrm{NaCl}$, (pH 8.0)). After the solution in the well was discarded, the second blocking solution (1\% BSA in PBS containing 0.6\% trizma base and $0.8 \%$ $\mathrm{NaCl}, \mathrm{pH}$ 8.0) was added, and incubated for $1 \mathrm{~h}$ at room temperature to obtain the pre-coated well plate. Samples were added to the well in duplicate, and incubated for $3 \mathrm{~h}$ at room temperature. The wells were then washed five times with washing solution and goat antimouse IgE-HRP conjugate was added and incubated for $30 \mathrm{~min}$ at room temperature. The wells were washed an additional five times with the washing solution and the plate was developed using a substrate solution containing $0.04 \% \quad o$-phenylenediamine and $0.0002 \% \mathrm{H}_{2} \mathrm{O}_{2}$ (100 $\mu \mathrm{L} /$ well). The reaction was terminated by the addition of $6 \mathrm{~N} \mathrm{H}_{2} \mathrm{SO}_{4}(100 \mu \mathrm{L} /$ well $)$, and absorbance at $492 \mathrm{~nm}$ was measured using a microplate reader (Wako). The total IgE levels were calculated using a standard curve generated using mouse IgE.

Assessment of the expression of COX-2 in the skin and serum was carried out using the immunoblotting method. An aliquot of the samples ( $4 \mu \mathrm{g}$ protein) was dissolved into $5 \mu \mathrm{L}$ of a 3-(3-cholamidepropyl) dimethyl-ammonio-1-propanesulphonate (CHAPS) cell extract buffer (100 mM piperazine-1,4-bis(2-ethnesulfonic acid) (PIPES), 4 mM EDTA, 0.2\% (w/v) CHAPS, $110 \mathrm{~mm}$ DTT, $40 \mu \mathrm{g} / \mathrm{mL}$ leupeptin, $20 \mu \mathrm{g} / \mathrm{mL}$ pepstatin-A, $20 \mu \mathrm{g} / \mathrm{mL}$ aprotinin, $2 \mathrm{mM}$ PMSF, $\mathrm{pH}$ 6.8). After the mixture was incubated for $20 \mathrm{~min}$ in an ice bath, $125 \mathrm{~mm}$ Tris-HCl buffer ( $\mathrm{pH}$ 6.8), including 4\% sodium dodecyl sulphate (SDS), 20\% glycerol, 0.01\% (w/v) bromophenol blue and $0.55 \%(\mathrm{w} / \mathrm{v})$ mercaptoethanol was added, and incubated at $100^{\circ} \mathrm{C}$ for $30 \mathrm{~s}$. The mixture was subjected to $0.1 \%$ SDS-polyacrylamide gel electrophoresis (PAGE) and blotted onto Immobilon transfer membranes (Millipore, MA, USA). The membranes were washed twice with a $25 \mathrm{mM}$ Tris buffer, containing $137 \mathrm{~mm} \mathrm{NaCl}, 2.7 \mathrm{mM} \mathrm{KCl}$, and 0.05\% Tween-20 (pH $7.4)$, and then incubated in a blocking solution $(25 \mathrm{~mm}$ Tris, $137 \mathrm{~mm} \mathrm{NaCl}, 2.7 \mathrm{~mm} \mathrm{KCl,} \mathrm{0.05 \%} \mathrm{Tween-20} \mathrm{and}$ $2 \%$ BSA, $\mathrm{pH} 7.4$ ) for $1 \mathrm{~h}$ at room temperature. The membranes were incubated with anti-mouse COX-2 $(1: 1,000)$ and anti-mouse $\beta$-actin in Tris buffered saline (TBS, $25 \mathrm{mM}$ Tris, $137 \mathrm{mM} \mathrm{NaCl}, 2.7 \mathrm{mM} \mathrm{KCl}$ ) containing $2 \% \mathrm{BSA}$ at $4^{\circ} \mathrm{C}$ for $12 \mathrm{~h}$. Blots were washed with TBS, containing 0.05\% Tween-20, and incubated with HRP-linked anti-rabbit secondary antibody $(1: 2,000)$ for $1 \mathrm{~h}$ at $4^{\circ} \mathrm{C}$. After washing with a $0.05 \%$ Tween-20 in PBS, the HRP-labeled antibody was detected with the enhanced chemiluminescence detection system using a luminoanalyzer (FUJI Photo Film Co., Ltd., Tokyo, Japan). $\beta$-Actin was used as an internal standard.

Measurement of TNF- $\alpha$ and NF- $\kappa B$ in the skin and serum. The levels of total TNF- $\alpha$ and NF- $\kappa \mathrm{B}$ in the skin and serum were assessed by 96 -well ELISA using the TNF- $\alpha$ ELISA and NF- $\kappa$ B p 65 sandwich ELISA kits according to the manufacturers' protocols. The absorbance of each sample was measured at $450 \mathrm{~nm}$ using a microplate reader.

Statistical analysis. Results are presented as means \pm SE. All data were analyzed with Student's $t$-test or a one-way ANOVA followed by a Dunnett's t-test. The experimental data were considered to be statistically different when $p$-values were less than 0.05.

\section{RESULTS}

Changes in skin features of induced-dermatitis in PC-treated NC/Nga mice

As shown in Fig. 1, 3-wk-old NC/Nga mice were sensitized with the application of $\mathrm{PC}$ on their backs, with 


\section{[TBARS]}

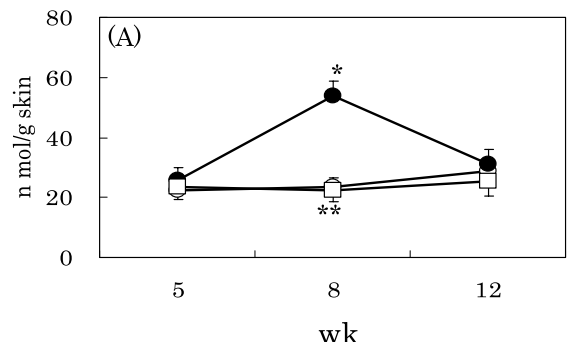

[Vitamin E]

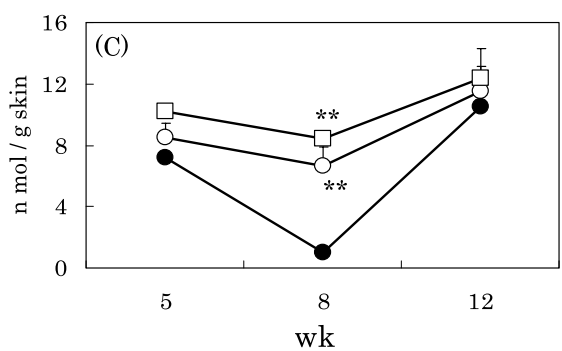

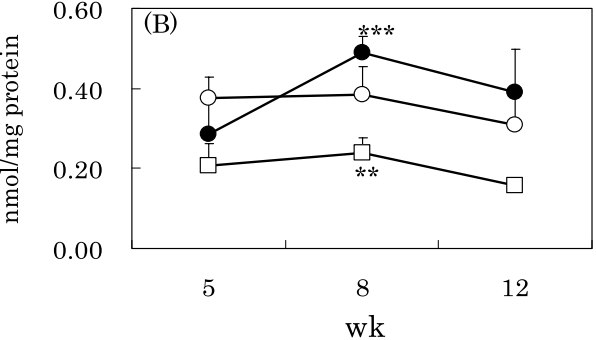

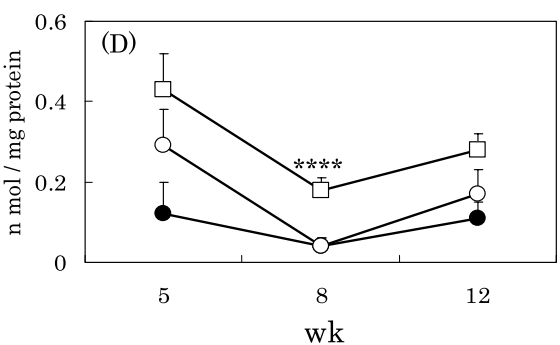

Fig. 2. AD-associated changes in the levels of TBARS and vitamin $\mathrm{E}$ in the skin and serum of NC/Nga mice. (A) Skin TBARS, (B) Serum TBARS, (C) Skin vitamin E, (D) Serum vitamin E. NC/Nga control mice (O), PC-applied NC/Nga mice $(\bullet)$, and vitamin E-treated NC/Nga mice with the PC-application $(\square) .{ }^{*} p<0.003$ vs. control at $5 \mathrm{wk},{ }^{* *} p<0.001$ vs. PCapplied mice at $8 \mathrm{wk},{ }^{* * *} p<0.01 \mathrm{vs.} \mathrm{control} \mathrm{at} 5 \mathrm{wk},{ }^{* * * *} p<0.01 \mathrm{vs}$. PC-applied mice at $8 \mathrm{wk} ; n=9$ for each group of mice.
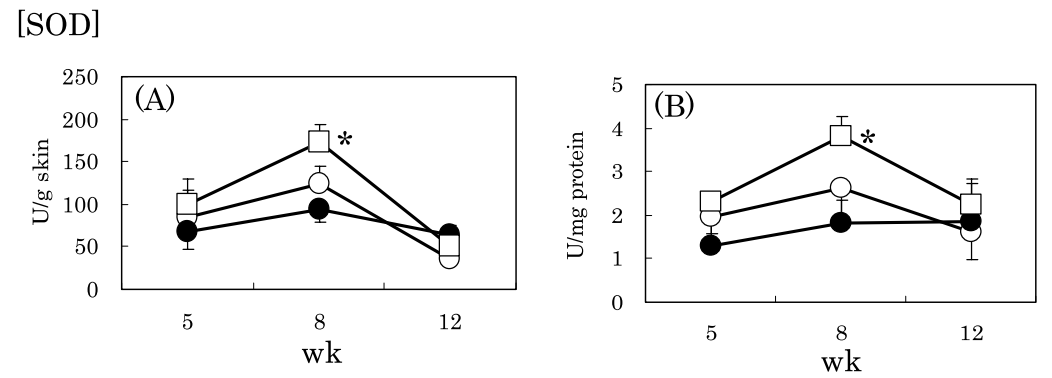

[Catalase]
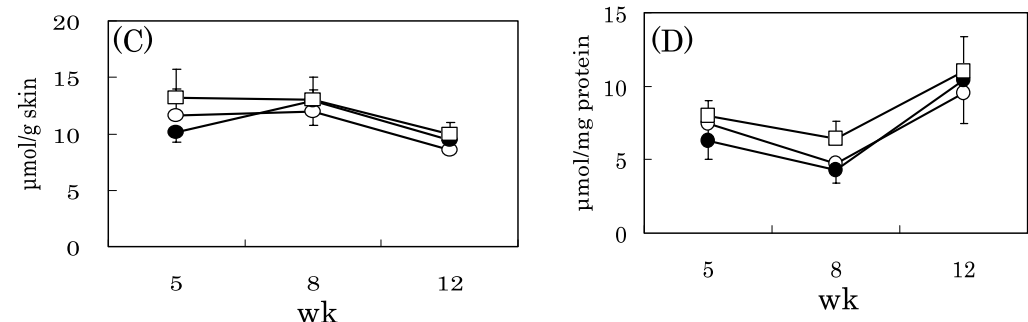

$[\mathrm{GSHPx}]$
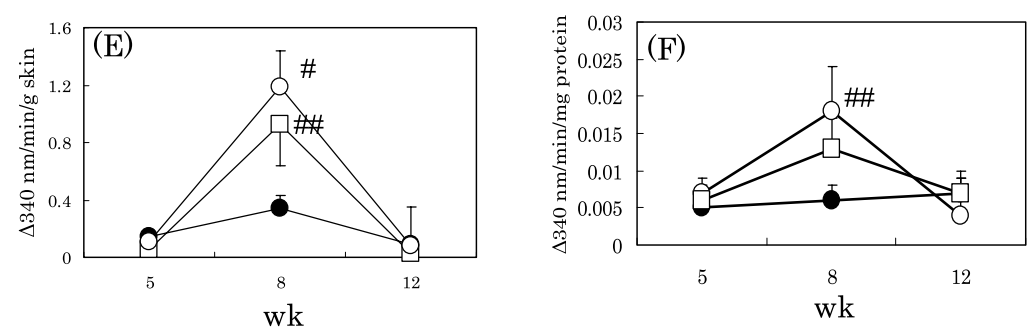

Fig. 3. AD-associated changes in the activities of SOD, catalase and GSHPx in the skin and serum of NC/Nga mice. (A) Skin SOD, (B) Serum SOD, (C) Skin catalase, (D) Serum catalase, (E) Skin GSHPx, (F) Serum GSHPx. NC/Nga control mice (O), PC-applied NC/Nga mice $(\bullet)$, and vitamin E-treated NC/Nga mice with the PC-application $(\square) .{ }^{*} p<0.01,{ }^{* *} p<0.005$, ${ }^{\#} p<0.004,{ }^{\# \#} p<0.01$ vs. NC/Nga control mice at $8 \mathrm{wk} ; n=9$ for each group of mice. 
$\operatorname{Ig} \mathrm{E}$
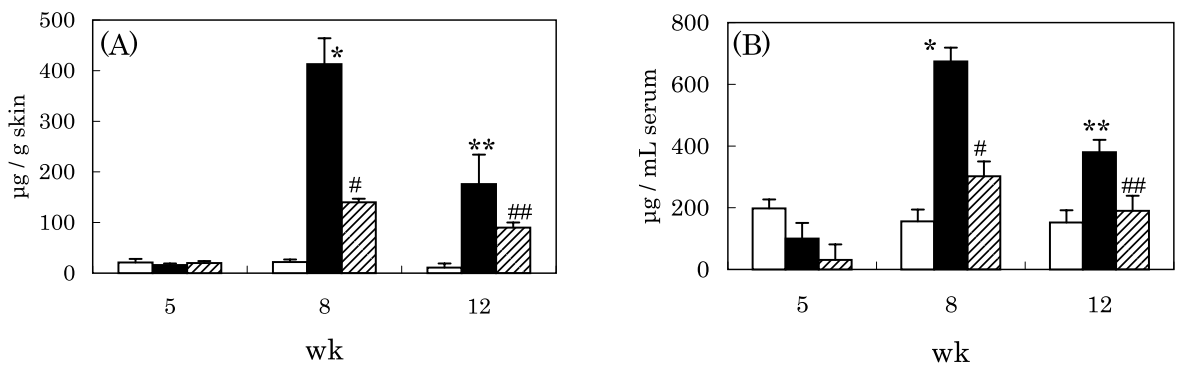

$\mathrm{COX}-2$
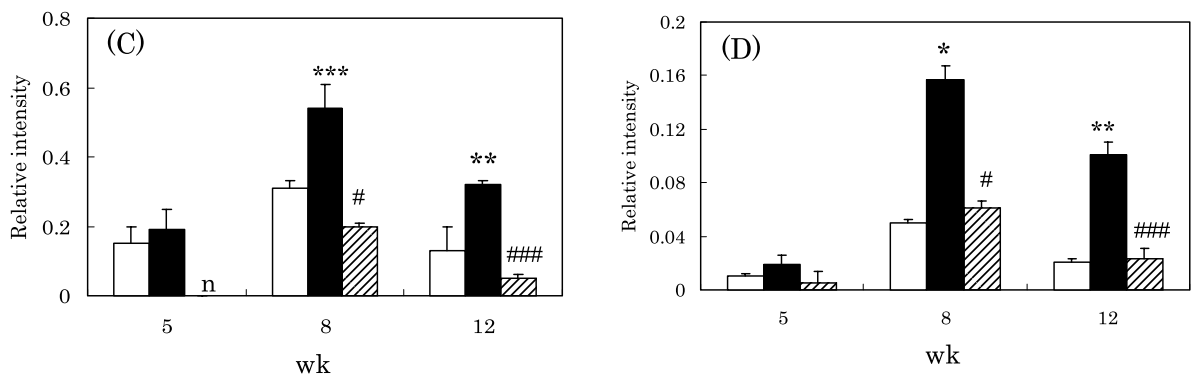

Fig. 4. PC-induced alterations in the expression of IgE and COX-2 in the skin and serum of NC/Nga mice. (A) Skin IgE, (B) Serum IgE, (C) Skin COX-2, (D) Serum COX-2. NC/Nga control mice (open column), PC-applied mice (black column), and vitamin E-treated mice with the PC-application (slashed column); ${ }^{*} p<0.001$ vs. control at $5 \mathrm{wk},{ }^{* *} p<0.005,{ }^{*} p<0.006$ vs. PC-applied mice at $8 \mathrm{wk},{ }^{\# \#} p<0.01,{ }^{\# \# \#} p<0.003$ vs. PC-applied NC mice at $12 \mathrm{wk} ; n=9$ for each group of mice.

TNF- $\alpha$
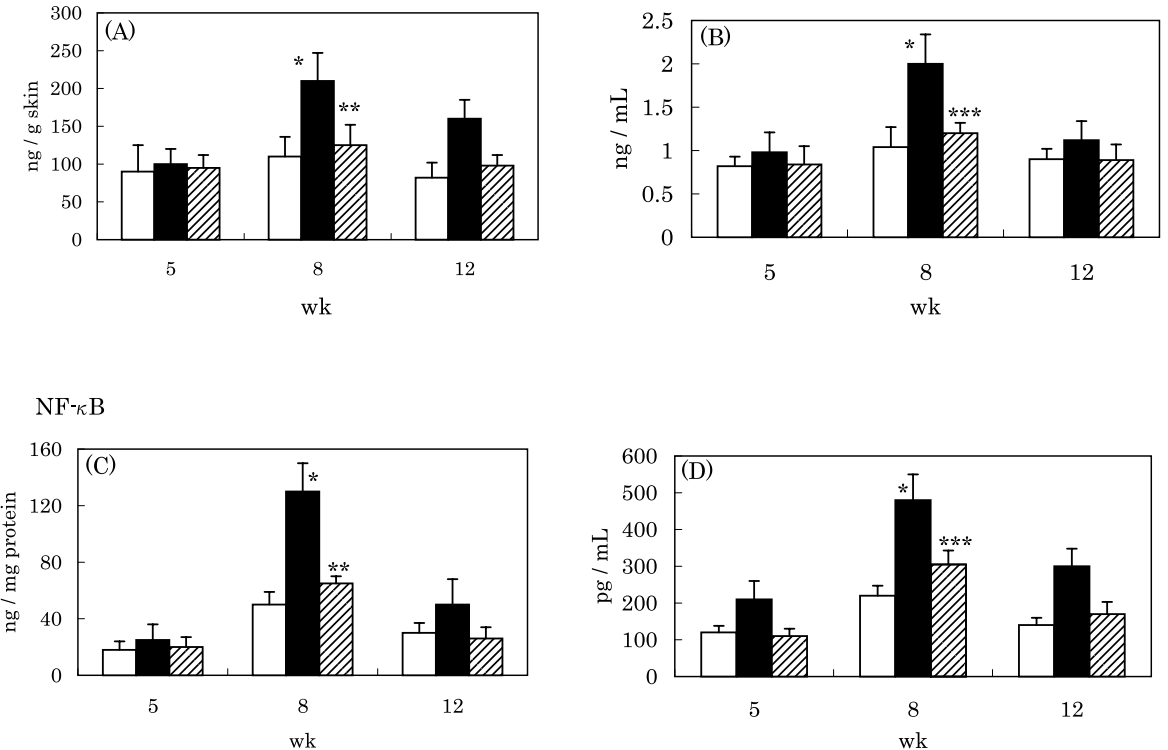

Fig. 5. PC-induced alterations in the levels of TNF- $\alpha$ and NF- $\kappa$ B in the skin and serum of NC/Nga mice. (A) Skin TNF- $\alpha$, (B) Serum TNF- $\alpha$, (C) Skin NF- $\kappa$ B, (D) Serum NF- $\kappa$ B. NC/Nga control mice (open column), PC-applied mice (black column), and vitamin E-treated mice with the PC-application (slashed column); ${ }^{*} p<0.001$ vs. control at $5 \mathrm{wk},{ }^{* *} p<0.01$, *** $p<0.05$ vs. C-applied NC/Nga mice at $8 \mathrm{wk} ; n=9$ for each group of mice.

mild inflammation appearing $2 \mathrm{wk}$ later. Thereafter, the inflammatory symptoms worsened, and the severest inflammation was observed $3 \mathrm{wk}$ later (at $8 \mathrm{wk}$ of age). Subsequently, the severity diminished and was healed by $4 \mathrm{wk}$ later (at $12 \mathrm{wk}$ of age), with the regrowth of hair on their backs. At the severest stage of symptoms, itching, erythematic lesions, hemorrhage, scaling and depilation were observed. Vitamin E-treated mice, with and without PC application, exhibited less inflammatory symptoms than PC-treated mice.

Changes in TBARS and vitamin E levels during the symptomatic cycle of $A D$

TBARS levels in the skin (Fig. 2A) and serum (Fig. 2B) were highly increased at the severest stage of 
inflammation after PC application, with levels decreasing toward normal values by $12 \mathrm{wk}$, as shown in Fig. 2 . Conversely, the vitamin E content in the skin (Fig. 2C), and plasma (Fig. 2D) decreased markedly. However, vitamin E-treated mice did not show an increase in TBARS levels even with application of PC.

Changes in the activity of antioxidant enzymes during the symptomatic cycle of $A D$

As shown in Fig. 3, the activities of SOD, catalase and glutathione peroxidase (GSHPx) in the skin (A, C and E) and plasma (B, D and F) of PC-treated mice did not increase significantly during the stage of severest symptoms. The levels were similar to control values, except for the level of GSHPx. PC and vitamin E treatment did not induce changes in catalase activity during the period of evaluation. However, treatment with vitamin E resulted in more significant increases in SOD and GSHPx activity than those of control mice at the peak stage of severity.

Changes in IgE and COX-2 levels during the symptomatic cycle of $A D$

As shown in Fig. 4, PC-treated mice showed marked increases in the levels of IgE and COX-2 in both skin (A and $C$ ) and plasma (B and D) at the peak stage of severity, with levels lowered by $12 \mathrm{wk}$. This pattern is similar to the changes observed in Figs. 2 and 3. Vitamin E treatment produced a marked inhibition, approximately $50-70 \%$, of the PC-induced increases in these factors. COX-2, in particular, was not detected at $5 \mathrm{wk}$ in the skin of the vitamin E-treated mice.

Changes in TNF- $\alpha$ and NF- $\kappa$ B levels during the symptomatic cycle of $A D$

The levels of the inflammatory factors TNF- $\alpha$ and NF$\kappa \mathrm{B}$ also underwent $\mathrm{PC}$-induced alterations. The levels of TNF- $\alpha$ in the skin (Fig. 5A and C) and plasma (Fig. 5B and D) at $8 \mathrm{wk}$ increased by approximately two-fold compared to the levels at $5 \mathrm{wk}$. Similarly, PC-treatment increased the levels of NF- $\kappa \mathrm{B}$ by approximately $2-3$ fold at the stage of peak severity. Again, the levels of these factors returned to normal by $12 \mathrm{wk}$. Consistent with the previous results, it was found that vitamin E significantly reduced the degree of changes during the symptomatic cycle of $\mathrm{AD}$.

\section{DISCUSSION}

It is thought that $\mathrm{AD}$ patients are subjected to oxidative stress, and hence the resultant ROS and lipid peroxides may play a part in $\mathrm{AD}$ pathogenesis $(5,7)$. In children with $\mathrm{AD}$, the urinary concentration of acrolein $\left(\mathrm{CH}_{2}=\mathrm{CH}-\mathrm{CHO}\right)$, which is a lipid peroxidation product with toxic activity, is markedly higher than in normal children $(6,16)$. Kapun et al. also suggested that significantly elevated plasma malondialdehyde levels were found in canine AD patients (17). These findings indicate that oxidative stress, with increased lipid peroxidation, is involved in the pathophysiology of $\mathrm{AD}$. In this study, mice treated with an application of PC allergen to the back showed a marked increase in TBARS levels in the skin and serum at the peak stage of AD symptoms, with the levels decreasing toward normal levels as symptoms subsided (Figs. 1 and 2). Accordingly, the levels of the antioxidant vitamin $\mathrm{E}$ in the skin and serum significantly decreased at the peak symptomatic stage and recovered to normal levels as symptoms subsided. When mice were treated subcutaneously with vitamin E, PC-induced changes in the levels of TBARS and vitamin $\mathrm{E}$ at the stage of peak symptom severity were markedly inhibited (Figs. 1 and 2). These results suggest that not only does PC treatment induce oxidative stress in NC/Nga mice, thereby generating ROS and resulting in the development of $\mathrm{AD}$ symptoms, but also that vitamin E may relieve and/or inhibit the development of $\mathrm{AD}$ symptoms. Little is known about whether or not the changes in vitamin $\mathrm{E}$ in $\mathrm{AD}$ are correlated with other antioxidants in a systematic relationship. Therefore, we analyzed the activities of the antioxidant enzymes SOD, catalase and GSHPx in the skin and serum with respect to the development of $\mathrm{AD}$ symptoms. As shown in Fig. 3, the activities of these enzymes in the skin and the serum did not increase at the stage of peak severity. When the animals were treated with vitamin E, the levels of SOD and GSHPx increased markedly at peak severity, followed by a regression toward normal levels. These results imply that the low activities of SOD and GSHPx at $8 \mathrm{wk}$ after PC-treatment are due to consumption of these enzymes during antioxidation of ROS without supplementation from other organs. This notion may explain the finding that vitamin E treatment increases SOD and GSHPx activity during peak severity. Thus, the antioxidant network system works to protect against inflammation in AD. However, it is currently unclear why the activity of GSHPx in control mice increased at $8 \mathrm{wk}$. Further detailed investigation into this matter is necessary. It is known that catalase is active in the presence of excess $\mathrm{H}_{2} \mathrm{O}_{2}$ concentrations; in contrast, GSHPx is active at low concentrations. Furthermore, GSHPx is capable of eliminating lipid hydroperoxides, which may be implicated in the pathogenesis of AD. Consequently, GSHPx may be active during peak severity, rather than catalase, due to the low concentration of $\mathrm{H}_{2} \mathrm{O}_{2}$ and high levels of lipid hydroperoxides in the skin. Thus, the imbalance between ROS generation and detoxification, by antioxidants, through a breakdown in the antioxidant network results in oxidative stress in $\mathrm{AD}$, culminating in an inflammatory event. Our results indicate that vitamin E treatment counteracts the disruption of the network, leading to prevention and/or healing of $\mathrm{AD}$ symptoms (Figs. 1 and 2). COX-2 is involved in prostaglandin $\mathrm{E}_{2}$ (PGE2) biosynthesis in the arachidonate metabolic cascade pathway through its induction of ROS. Consequently, overproduction of ROS, caused by COX-2 activation, may further exacerbate inflammation in AD. Hence, it is widely accepted that alterations in COX-2 expression, and the abundance of its enzymatic product prostaglandin $\mathrm{E}_{2}\left(\mathrm{PGE}_{2}\right)$, play key roles in the development of inflammation. Furthermore, PGE2 production activates Th2 cells to secrete inflammatory cytokines, such as IL-5, which stimulate B-cells to induce IgE. It is recognized that high levels of IgE are one of the charac- 
teristics of $\mathrm{AD}$, and clinical observations suggest a correlation between serum IgE levels and the extent of disease (18-20). Therefore, we assessed changes in COX-2 and IgE levels associated with the symptomatic cycle of $\mathrm{AD}$ in this study. As indicated by previous reports, IgE levels in PC-treated mice were enhanced markedly in the skin and serum (Fig. 4) at peak severity. When AD symptoms regressed, the levels of IgE decreased to levels observed in control mice. The PC-induced increase in IgE was suppressed $(\sim 60 \%)$ by vitamin $\mathrm{E}$ treatment. Similar to the changes in IgE, the activity of COX-2 was also markedly increased at peak severity, and subsequently decreased to normal levels when symptoms regressed. Vitamin E-treated mice showed significant inhibition of PC-induced IgE production. Interestingly, COX-2 was not detected in the vitamin E-treated skin at the pre-symptomatic stage (Fig. 4). These findings indicate that $\mathrm{PC}$-induced $\mathrm{AD}$-like skin inflammation is caused by oxidative stress generated through COX-2 activation (21), resulting in elevated production of $\operatorname{IgE}$ via B-cell stimulation. Furthermore, vitamin E decreases PGE2 production due to its inhibition of COX-2 activation, leading to moderation of the inflammatory process in $\mathrm{AD}$. It is known that the macrophage-derived proinflammatory cytokine, TNF- $\alpha$, may play a crucial role in $\mathrm{AD}$ (22-24). Large amounts of $\mathrm{TNF}-\alpha$ are quickly released by stimulated mast cells. All inflammatory cells express TNF- $\alpha$ receptors, and respond to TNF$\alpha$ activation with further TNF- $\alpha$ production. TNF- $\alpha$ expression is regulated by activation of the transcription factor $\mathrm{NF}-\kappa \mathrm{B}$, which is important in the activation of host immune responses, and TNF- $\alpha$ itself triggers NF$\kappa \mathrm{B}$ activation (10). Consequently, it is important to assess changes in these inflammatory factors during the symptomatic cycle of AD. As shown in Fig. 5, PC treatment markedly increased the expression of TNF- $\alpha$ in the skin and serum during peak severity, and declined as symptoms subsided. In accordance with the changes in TNF- $\alpha$, the expression of NF- $\kappa \mathrm{B}$ was increased markedly in the skin and serum. Vitamin Etreated mice showed a marked inhibition of TNF- $\alpha$ and $\mathrm{NF}-\kappa \mathrm{B}$ expression, even when treated with PC. The results in this study are the first to suggest that biochemical indices in PC-treated mice change significantly during the pathophysiological cycle (moderatesevere-moderate allergic symptom), and that vitamin $\mathrm{E}$ markedly inhibits increases in these indices through its antioxidant effect and/or non-antioxidative inhibition of inflammatory cytokines. Since it is thought that oxidative stress-induced ROS production may promote the activation of $\mathrm{NF}-\kappa \mathrm{B}$, vitamin $\mathrm{E}$ may control cellular signaling by modulating NF- $\kappa \mathrm{B}$ activation. In fact, it has been suggested that NF- $\kappa \mathrm{B}$ inhibitor improves $\mathrm{AD}$ in NC/NgaTnd mice (25).

On the basis of these results, it is expected that the observed alterations in biochemical indices, which reflect the symptomatic cycle, may be applicable to objective diagnosis and treatment for atopic dermatitis, and that vitamin E may improve the symptoms of $\mathrm{AD}$. However, further detailed investigations are necessary for the establishment of a theory.

\section{Acknowledgments}

We would like to gratefully acknowledge Misses Ayako Matsushima, Yumi Kurima, Rie Kobayashi, Aki Yonezawa, and Haruka Suzuki, as well as Messrs. Makio Tanami and Syogo Tsuji for their technical assistance.

\section{REFERENCES}

1) Thepen T, Langeveld-Wildschut EG, Bihari IC, van Wichen DF, van Reijse FC. 1996. Biphasic response against aeroallergen in atopic dermatitis showing a swichfrom an initial Th2 response to a Th1 response in situ. J Allergy Clin Immunol 97: 828-837.

2) Grewe M, Bruijinzeel-Koomen C, Schpf E, Thepen T, Langeveld-Wildschut AG. 1998. A role for Th1 and Th2 cells in the immunopathogenesis of atopic dermatitis. Immunol Today 19: 359-361.

3) Homey B, Steinhoff M, Ruzicka T, Leung DY. 2006. Cytokines and chemokines orchestrate atopic skin inflammation. J Allergy Clin Immunol 118: 178-189.

4) Ahn JY, Choi SE, Jeong MS, Park KH, Moon NJ, Joo SS, Lee CS, Choi YW, Li K, Lee MK, Lee MVV, Seo SJ. 2010. Effect of taxifolin glycoside on atopic dermatitis-like skin lesions in NC/Nga mice. Phytother Res 24: 1071-1077.

5) Omata N, Tsukahara H, Ito S, Ohshima Y, Yasutomi M, Yamada A, Jiang M, Hiraoka M, Nambu M, Deguchi Y, Mayumi M. 2001. Increased oxidative stress in childhood atopic dermatitis. Life Sci 69: 223-228.

6) Tsukahara H, Shibata R, Ohshima Y, Todoroki Y, Sato S, Ohta N, Hiraoka M, Yoshida A, Nishima S, Mayumi M. 2003. Oxidative stress and altered antioxidant defenses in children with acute exacerbation of atopic dermatitis. Life Sci 72: 2509-2516.

7) Aly DG, Shahin RS. 2010. Oxidative stress in lichen planus. Acta Dermatoven APA 19: 3-11.

8) Bradley JR. 2008. TNF-mediated inflammatory disease. J Pathol 214: 149-160.

9) Hayden MS, Ghosh S. 2008. Shared principles in NF- $\kappa$ B signaling. Cell 132: 344-362.

10) Ghosh S, Karin M. 2002. Missing pieces in the NF- $\kappa \mathrm{B}$ puzzle. Cell 109: S81-S96.

11) Traber MG, Packer L. 1995. Vitamin E: beyond antioxidant function. Am J Clin Nutr 62: 1501S-1509S.

12) Nazrun AS, Norazlina M, Norliza M, Nirwana, SI. 2012. The anti-inflammatory role of vitamin $\mathrm{E}$ in prevention of osteoporosis. Adv Pharmacol Sci 2012, 142702.

13) Ohkawa H, Onishi N, Yagi K. 1979. Assay for lipid peroxides in animal tissues by thiobarbituric acid reaction. Anal Biochem 95: 351-358.

14) Aebi H. 1984. Catalase in vitro. Methods Enzymol 105: 121-126.

15) Flohe l, Gunzler WA. 1984. Assays glutathione peroxidase. Methods Enzymol 105: 114-121.

16) Uchida K, Kanematsu M, Sakai K, Matsuda T, Hattori N, Mizuno Y, Suzuki D, Miyata T, Noguchi N, Niki E, Osawa T. 1998. Protein-bound acrolein: Potential markers for oxidative stress. Proc Natl Acad Sci USA 95: 48824887.

17) Kapun AP, Salobir J, Levart A, Kotnik T, Svete AN. 2012. Oxidative stress markers in canine atopic dermatitis. Res Vet Sci 92: 469-470.

18) Matsuda H, Watanabe N, Geba GP, Sperl J, Tsudzuki M, 
Hiroi J, Matsumoto M, Ushio H, Saito S, Askenase PW, Ra C. 1997. Development of atopic dermatitis-like lesion with IgE hyperproduction in NC/Nga mice. Int Immunol 9: 461-466.

19) Leung, DYM. 2000. Atopic dermatitis: new insights and opportunities for therapeutic intervention. J Allergy Clin Immunol 32: 860-876.

20) Oomizu S, Onishi N, Suzuki H, Ueda K, Mochizuki M, Morimoto K, Kawamoto S, Ono K, Kameyoshi Y, Hide M. 2006. Oral administration of pulverized Konjac glucomannan prevents the increase of plasma immunoglobulin $\mathrm{E}$ and immunoglobulin $\mathrm{G}$ levels induced by the injection of syngeneic keratinocyte extracts in $\mathrm{BALB} / \mathrm{c}$ mice. Clin Exp Allergy 36: 102-110.

21) Wu D, Hayek MG, Meydani S. 2001. Vitamin E and macrophage cyclooxygenase regulation in the aged. $J$ Nutr 131: 382S-388S.

22) Marble DJ, Gordon KB, Nickoloff BJ. 2007. Targeting $\mathrm{TNF} \alpha$ rapidly reduces density of dendritic cells and mac- rophages in psoriatic plaques with restoration of epidermal keratinocyte differentiation. J Dermatol Sci 48: 87101.

23) Wang H, Peters T, Kess D, Sindrilaru A, Oreshkova T, Van Rooijen N, Stratis A, Renkl AC, Sunderkotter C, Wlaschek M, Scharffetter-Kochanek K. 2006. Activated macrophages are essential in a murine model for $\mathrm{T}$ cellmediated chronic psoriasiform skin inflammation. J Clin Invest 116: 2105-2114.

24) Stratis A, Pasparakis M, Rupec RA, Markur D, Hartmann K, Scharffetter-Kochanek K, Peters T, Van Rooijen N, Krieg T, Haase I. 2006. Pathogenic role for skin macrophages in a mouse model of keratinocyte-induced psoriasis-like skin inflammation. J Clin Invest 116: 20942104.

25) Tanaka A, Muto S, Jung K, Itai A, Matsuda H. 2007. Topical application with a new NF- $\kappa \mathrm{B}$ inhibitor improves atopic dermatitis in NC/NgaTnd mice. J Invest Dermatol 127: 855-863. 